\title{
Leukocyte counts and macrophage phenotypes in induced sputum and bronchoalveolar lavage fluid from normal subjects
}

\author{
C. Lensmar*, G. Elmberger**, P. Sandgren*, C.M. Sköld*, A. Eklund*
}

Leukocyte counts and macrophage phenotypes in induced sputum and bronchoalveolar lavage fluid from normal subjects, C. Lensmar, G. Elmberger, P. Sandgren, C.M. Sköld, A. Eklund. CERS Journals Ltd 1998.

ABSTRACT: It is unclear whether leukocytes in induced sputum (IS) and bronchoalveolar lavage (BAL) represent the same cell populations. To compare leukocyte counts and macrophage phenotypes and investigate any measurable dithiothreitol (DTT)-mediated effect on macrophage immunocytochemical staining results, IS and BAL samples from nine healthy smokers and seven nonsmokers were examined.

BAL and IS samples were processed and cell viability and cell counts were assessed. The macrophages were characterized by seven monoclonal antibodies (RFD1, RFD7, CD11b, CD54, CD68, CD71 and HLA-DR) using an indirect immunoalkaline phosphatase method.

Intraindividual comparison of IS and BAL showed that IS samples from smokers and nonsmokers contained a lower total cell count $(p<0.01$ smokers, $p<0.05$ nonsmokers), a lower percentage of macrophages (both $p<0.05$ ) and a higher percentage of neutrophils (both $\mathbf{p}<0.05$ ) than BAL samples. In addition, nonsmokers sputum samples contained a lower proportion of lymphocytes $(p<0.05)$ than BAL. The macrophage expression of RFD7 and CD71 was higher in smokers sputum samples (both $\mathbf{p}<\mathbf{0 . 0 5}$ ) than in BAL, while nonsmokers sputum macrophages showed a higher expression of CD54 and CD71 (both $\mathbf{p}<0.05$ ) than BAL macrophages. DTT-incubated BAL samples showed no difference in macrophage antigen expression from BAL samples not exposed to DTT.

In conclusion, the relative proportions of leukocytes and the macrophage phenotypes differed between induced sputum and bronchoalveolar lavage suggesting that the methods provide samples from different lung compartments, inhabited by cells with different phenotypes.

Eur Respir J 1998; 12: 595-600.
*Dept of Medicine, Division of Respiratory Medicine and **Dept of Pathology, Division of Cytology, Karolinska Hospital, Stockholm, Sweden.

Correspondence: C. Lensmar

Lung Research Laboratory

L201

Division of Medicine

Karolinska Hospital

S-17176 Stockholm

Sweden

Fax: 46851775451

Keywords: Antigen expression bronchoalveolar lavage

induced sputum

macrophages

three-step alkaline phosphatase method

Received: June 301997

Accepted after revision April 211998

Generously supported by grants from the Swedish Council for Work Life Research (grant 95-0251), the Swedish Heart-Lung Foundation and the Karolinska Institute and by a donation from A. Koolberg, Vancouver, Canada
Bronchoalveolar lavage (BAL) is a well-standardized method for retrieving cells and soluble material from the lung. An alternative, less invasive method to recover such material is induced sputum (IS). The method provides an opportunity to perform frequent observations, in order to follow a dynamic course of pulmonary inflammatory disease and effects of treatment. Recent research on IS has focused on markers of inflammation in asthma and the method has, in that context, proven to be reliable, for instance in the evaluation of airway eosinophilia [1-9].

There is still, however, a need to determine the degree of correlation between IS and BAL material and to establish baseline values for IS variables in healthy individuals. The main difference between the processing of IS and BAL is the incubation of sputum material with a disulphide reducing agent, dithiothreitol (DTT), which is carried out to obtain cell dispersion [10]. Incubation of samples with DTT allows a high repeatability in differential cell counts, but has been shown to interfere with immunological detection of some cellular antigens, for example, the intracellular expression of eosinophil cationic protein, EG2 [10].

The most predominant cell in the alveolar and airway lining fluid is the macrophage. Studies of material recruited from the airways and alveoli separately [11] have implied the presence of morphologically different subsets of macrophages deriving from different levels of the bronchoalveolar tree.

The present study was conducted to determine intraindividual differences in cell-count data and macrophage phenotypes in IS and BAL collected from healthy smokers and nonsmokers and to investigate any measurable DTTmediated effect on macrophage immunocytochemical staining results.

\section{Materials and methods}

\section{Subjects}

IS and BAL fluid samples were collected from 16 subjects; nine smokers, six females and three males, mean age 27.9 yrs (range 21-38) and seven nonsmokers, five females and two males, mean age 26.6 yrs (range 19-38). The smokers mean cigarette consumption was $10.4 \pm 7.2$ pack-yrs $($ mean \pm sD), and present consumption exceeded 10 cigarettes $\cdot$ day $^{-1}$ for the last 5 yrs.

All subjects had normal pulmonary radiographs and showed no clinical signs of respiratory disease. IS samples 
were collected at a first visit and the subjects underwent BAL on a second visit within 4 weeks.

Three additional BAL samples from healthy nonsmokers, two females and one male, mean age 39 yrs (range 33-46), were included in the BAL comparison study between smokers and nonsmokers. Since these samples were collected before the induced sputum method was established in our clinic, sputum samples were not available. The study was approved by the local Ethics Committee and informed consent was obtained.

\section{Sputum induction}

After pretreatment with inhaled $200 \mu \mathrm{g}$ salbutamol (Ventolin®; Glaxo, Ware, UK), sputum was induced by inhalation of $3.5 \%$ sterile saline solution (Apoteksbolaget, Stockholm, Sweden). The saline was nebulized with an ultrasonic nebulizer (DeVilbiss Ultraneb 2000; DeVilbiss, Somerset, PA, USA) and inhaled for up to $20 \mathrm{~min}$. After 5 min and at subsequent 3-5 min intervals subjects were asked to rinse their mouths, blow their noses and cough sputum into clean polypropylene tubes, kept on ice. The first and third expectorated sputum portions were pooled and stored for future analysis and the second expectorated portion was collected in a separate tube, for use in cell analysis. The collection of sputum for cell analysis was interrupted when the volume of the sample reached $7 \mathrm{~mL}$.

\section{Bronchoalveolar lavage}

BAL was performed by wedging a flexible fibreoptic bronchoscope (Olympus BF Type P20; Olympus Optical Co., Tokyo, Japan) in a subsegment in the right middle lobe. Five aliquots of $50 \mathrm{~mL}$ sterile phosphate-buffered saline solution at $+37^{\circ} \mathrm{C}$ were instilled. The fluid was gently aspirated after each instillation, pooled and collected in a siliconized bottle. The material was kept on ice and immediately transported to the laboratory.

\section{Handling of cells}

Induced sputum. The $7 \mathrm{~mL}$ sputum sample was dispersed with 2 mL 0.5\% DTT (Sigma Aldrich Co., St. Louis, MO,
USA) diluted in Hanks balanced salt solution (HBSS; Sigma), carefully mixed and incubated until homogenized. Polypropylene vials were used to avoid cell adhesion. The sample was centrifuged at $128 \times \mathrm{g}$, and $4{ }^{\circ} \mathrm{C}$ for $10 \mathrm{~min}$ and the cell pellet was resuspended in $2 \mathrm{~mL}$ HBSS. Fifty microlitres of the cell suspension was used to assess viability by trypan blue cell exclusion and to determine the total cell count in a Bürker chamber. Cytospins were prepared using aliquots of cell suspension equivalent to 60,000 cells per slide. The material was centrifuged at $22.4 \times \mathrm{g}$ for $3 \mathrm{~min}$ in a cytocentrifuge (Cytospin 2; Shandon, Runcorn, UK), stained in May-Grünwald Giemsa for differential cell counts or stored at $-70^{\circ} \mathrm{C}$ until further processing. To determine cell differentials, 400 cells were counted. The percentage of squamous cells was determined, but not included in the differential cell count. Cytospins containing $<80 \%$ squamous cells were considered adequate.

\section{Bronchoalveolar lavage}

The BAL fluid was strained through a single layer of Dacron nets (Type AP32; Millipore, Bedford, Ireland). Cells were centrifuged at $400 \times \mathrm{g}$ for $10 \mathrm{~min}$ at $+4^{\circ} \mathrm{C}$ and the cell pellet was resuspended in RPMI 1640 (Sigma). Total cell counts and assessment of viability by trypan blue cell exclusion were performed using a Bürker chamber. Cyto-spins for differential cell counts and immunocytochemical stainings were prepared as described above. After thorough blending 10 BAL samples were divided in two portions, with one portion incubated in $0.5 \%$ DTT for 10 min before processing and then processed as described previously.

\section{Immunocytological staining}

Seven monoclonal antibodies were used to characterize the macrophages phenotypically (table 1). The stainings were performed using a three-step, indirect immunoalkaline phosphatase (ALP) method. Frozen slides were slowly warmed to room temperature before processing. Slides

Table 1. - Panel of primary monoclonal antibodies used to characterize macrophages recovered with induced sputum and bronchoalveolar lavage

\begin{tabular}{|c|c|c|c|}
\hline Antibody (clone) & Specificity & Reactivity & Source \\
\hline Antihuman dendritic cells (RFDI) & $\begin{array}{l}\text { Reacts with an epitope within the HLA class } \\
\text { II complex }\end{array}$ & $\begin{array}{l}\text { Dendritic cells, nonreactive } \\
\text { with monocytes, granulocytes }\end{array}$ & Serotec \\
\hline $\begin{array}{l}\text { Antihuman mature macrophages } \\
\text { (RFD7) }\end{array}$ & $\begin{array}{l}\text { Reacts with an antigen expressed in mature tissue } \\
\text { phagocytes }\end{array}$ & Macrophages & Serotec \\
\hline $\begin{array}{l}\text { Antihuman C3bi receptor, CD11b, } \\
\text { (2LPM19c) }\end{array}$ & $\begin{array}{l}\text { Reacts with the cell surface receptor for the C3bi } \\
\text { complement fragment }\end{array}$ & $\begin{array}{l}\text { Granulocytes, monocytes, } \\
\text { tissue macrophages }\end{array}$ & Dako \\
\hline $\begin{array}{l}\text { Antihuman ICAM-1, CD54, } \\
\text { (6.5B5.(1)) }\end{array}$ & Reacts with human ICAM-1 & $\begin{array}{l}\text { Broad; leukocytes, endothelial } \\
\text { and epithelial cells }\end{array}$ & Dako \\
\hline $\begin{array}{l}\text { Antihuman macrophage, CD68 } \\
\text { (PG-M1) }\end{array}$ & $\begin{array}{l}\text { Reacts with an intracytoplasmic antigen probably } \\
\text { associated with lysosomal granules }\end{array}$ & $\begin{array}{l}\text { Macrophages, nonreactive with } \\
\text { antigen-presenting cells }\end{array}$ & Dako \\
\hline $\begin{array}{l}\text { Antihuman transferrin receptor } \\
\text { CD71 (Ber-T9) }\end{array}$ & Reacts with the transferrin receptor & $\begin{array}{l}\text { Proliferating cells, macro- } \\
\text { phages }\end{array}$ & Dako \\
\hline Antihuman HLA-DR (CR3/43) & $\begin{array}{l}\text { Reacts with the } \beta \text {-chain of all products of the DP, } \\
\text { DQ and DR subregions }\end{array}$ & Leukocytes & Dako \\
\hline Antihuman cytokeratin (MNF116) & $\begin{array}{l}\text { Reacts with an epitope present in a wide range of } \\
\text { cytokeratins }\end{array}$ & $\begin{array}{l}\text { Broad: human epithelial cells } \\
\text { (negative control) }\end{array}$ & Dako \\
\hline
\end{tabular}

ICAM: intracellular adhesion molecule; HLA: human leukocyte antigen. 
were fixed in $-20^{\circ} \mathrm{C}$ acetone for $10 \mathrm{~min}$ and rehydrated for 5 min in Tris-buffered saline (TBS), $\mathrm{pH} \mathrm{7.6,} \mathrm{containing}$ $1 \%$ bovine serum albumin (BSA). The slides were then incubated with $80 \mu \mathrm{L}$ of the appropriate dilutions of: primary monoclonal antibodies (table 1), ALP-conjugated rabbit anti-mouse antibody (Dako, Glostrup, Denmark) and ALP-conjugated swine antirabbit antibody (Dako), 30 min each. The incubations took place in humid chambers and the samples were carefully washed with TBS between the steps. The immunological reaction was visualized using freshly prepared ALP substrate (Phosphatase Fast Red Sigma solution, Sigma) containing $1 \mathrm{mmol} \cdot \mathrm{L}^{-1}$ levamisole (Sigma) to inhibit endogenous macrophage ALP activity. The enzyme-substrate reaction was interrupted with tap water and the slides were counterstained with Harris Haematoxylin (Histolab, Gothenburg, Sweden) for $30 \mathrm{~s}$, blued in tap water and air-dried. For mounting, Glycerine Mountant (Merck, Darmstadt, Germany) was used.

The slides were viewed with a light microscope (Nikon, Tokyo, Japan). The macrophages were identified on the basis of morphological features and positive cells were recognised by red staining (fig. 1). A minimum of 600 cells were counted by two independent observers and the mean value of the two observations was used. An irrelevant monoclonal antibody (MNF116, anti-human cytokeratin; Dako) negative for macrophages was used to assess background staining.

\section{Statistical analysis}

The data are presented as medians with upper and lower quartile values. Statistical comparisons were made using the nonparametric Mann-Whitney U-test for comparisons between smokers and nonsmokers and Wilcoxon matched-pairs test for intraindividual comparisons of BAL and sputum material from the same subject. A p-value $<0.05$ was considered significant.

\section{Results}

Intraindividual comparison of induced sputum and bronchoalveolar lavage cell-count data

No case had to be excluded from the study due to excessive squamous cell contamination of the sputum material. The cell viability did not differ between IS and BAL samples from smoking or nonsmoking individuals. In both groups, sputum material contained a lower total cell count than the BAL fluid $(\mathrm{p}<0.01$ smokers, $\mathrm{p}<0.05$ nonsmokers, table 2). Sputum samples from smokers as well as nonsmokers showed lower percentages of macrophages (both $\mathrm{p}<0.05)$ and higher percentages of neutrophils $(\mathrm{p}<0.05)$ in their differential cell counts compared with BAL samples. Additionally, nonsmokers' IS samples showed a lower percentage of lymphocytes $(p<0.05)$ than the BAL fluid samples, while no similar difference was detected between lymphocyte proportions in IS and BAL material from smokers. The percentage of eosinophils did not differ between IS and BAL material from smokers or nonsmokers. When comparing cell counts in sputum and a)

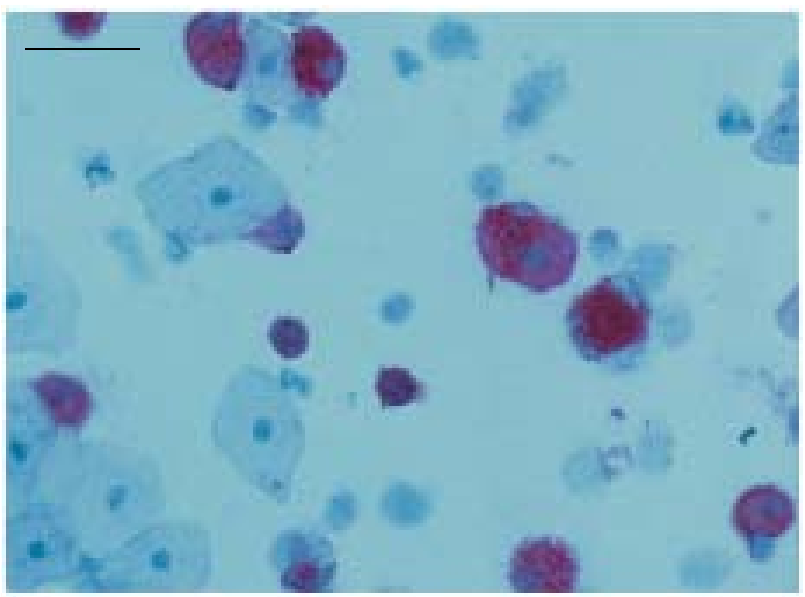

b)

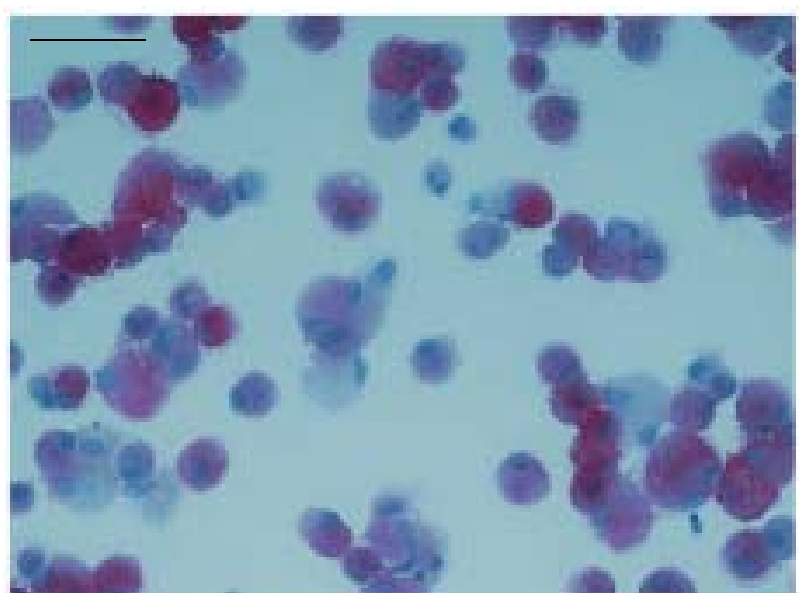

Fig. 1. - Three-step immunocytochemical stain for human leukocyte antigen (HLA) II on macrophages recovered with: a) induced sputum; and $\mathrm{b}$ ) bronchoalveolar lavage. Positivity shows as a strong red stain of the cytoplasm of the macrophages. (Internal scale bars $=1,000 \mu \mathrm{m}$.)

BAL fluid within the total population, without separation of smokers and nonsmokers, higher degrees of significance were reached (table 2).

Intraindividual comparison of induced sputum and bronchoalveolar lavage macrophage phenotypes

Macrophages collected with induced sputum differed phenotypically from those collected with BAL (table 3 ). Sputum macrophages showed a higher expression of CD71 $(\mathrm{p}<0.05)$ in both smokers and nonsmokers, compared with BAL macrophages.

Smokers had a significantly higher percentage of macrophages expressing RFD7 $(\mathrm{p}<0.05)$ in sputum samples, whereas the difference in RFD7 expression between nonsmokers sputum and BAL macrophages did not reach significant levels.

When comparing IS and BAL macrophage phenotypes in the total population (table 3), sputum macrophages showed a higher expression of RFD7 ( $<<0.01)$, CD71 ( $<<$ $0.01)$ and CD54 $(\mathrm{p}<0.05)$ than BAL macrophages. Furthermore, IS macrophages showed a higher expression of CD68 $(\mathrm{p}<0.05)$ than BAL macrophages. 
Table 2. - Intraindividual comparisons of viability, total (TCC) and differential cell counts in induced sputum (IS) and bronchoalveolar lavage (BAL) material collected from smokers and nonsmokers

\begin{tabular}{|c|c|c|c|c|c|c|c|c|c|}
\hline & \multicolumn{3}{|c|}{ Smokers } & \multicolumn{3}{|c|}{ Nonsmokers } & \multicolumn{3}{|c|}{ Total population } \\
\hline & $\underset{n=9}{\text { IS }}$ & & $\begin{array}{c}\text { BAL } \\
n=9\end{array}$ & $\underset{\mathrm{n}=7}{\mathrm{IS}}$ & & $\begin{array}{c}\text { BAL } \\
n=7\end{array}$ & $\begin{array}{c}\text { IS } \\
n=16\end{array}$ & & $\begin{array}{l}\text { BAL } \\
n=16\end{array}$ \\
\hline Viability & $88.9(81.0-93.0)$ & 88.5 & $(85.0-90.5)^{+}$ & $83.6(77.5-92.0)$ & 93.0( & $(84.5-95.0)^{+}$ & $86.0(80.4-93.0)$ & 89.3 & $(85.5-93.0)^{+}$ \\
\hline $\mathrm{TCC} \times 10^{6}$ & $1.9(1.0-2.1)$ & 54.6 & $(35.0-74.7)^{* *}$ & $0.6(0.4-2.6)$ & 13.7 & $(9.5-15.9)^{*}$ & $1.5(0.6-2.3)$ & 33.3 & $(14.4-62.3) * * *$ \\
\hline Macrophages & $59.2(52.4-80.4)$ & 97.2( & $(95.8-97.7)^{*}$ & $41.2(33.3-52.0)$ & 88.8( & $(85.3-91.0)^{*}$ & $52.0(41.2-76.0)$ & 95.4 & $(89.6-97.2) * * *$ \\
\hline cytes & $0.9(0.5-1.7)$ & 1.6 & $(1.0$ & $2.0(1.0-6.0)$ & 8.4 & $(6.6-11.0)^{*}$ & $1.2(0.6-4.0)$ & 2.3 & $(1.6-7.9)^{+}$ \\
\hline Neutrophils & $34.0(16.8-49.0)$ & 0.5 & $(0.3-1.7) *$ & $52.2(47.0-61.1)$ & 2.0 & $(1.4-2.4)^{*}$ & $47.0(18.2-53.6)$ & 1.4 & $(0.4-2.4) * * *$ \\
\hline Eosinophils & $0.4(0.2-0.6)$ & 1.1 & $(0.5-1.7)^{+}$ & 0.5 & 0.4 & $(-)^{+}$ & $0.4(0.2-0.8)$ & 0.6 & $(0.3-1.1)^{+}$ \\
\hline
\end{tabular}

The data are presented as medians of percentage values with upper and lower quartile values. $*: \mathrm{p}<0.05$, between IS and BAL; **: $\mathrm{p}<0.01$, between IS and BAL; ***: $\mathrm{p}<0.001$, between IS and BAL; +: Ns. Comparisons were made using Wilcoxon's matched pairs test.

The proportion of macrophages expressing CD54 was higher in nonsmokers sputum material $(\mathrm{p}<0.05)$. No corresponding difference in CD54 expression could be detected comparing IS and BAL material from smokers.

The macrophage expression of CD11b, HLA-DR and RFD1 did not differ significantly between IS and BAL in either smokers or nonsmokers.

\section{Dithiothreitol-exposed bronchoalveolar lavage immuno- staining results}

DTT-incubated BAL samples did not show any significant difference in macrophage antigen expression compared to BAL samples not exposed with DTT (data not shown). Since only three smoking subjects were included in the BAL-DTT-incubated BAL study, comparisons were made without separating staining results from smokers and nonsmokers.

Smokers versus nonsmokers: comparison of cell count data in sputum and bronchoalveolar lavage, respectively

The cell viability did not differ significantly between smokers and nonsmokers in IS or BAL material. The total cell count was higher in BAL fluid from smokers than from nonsmokers $(\mathrm{p}<0.001)$, while the total cell count did not differ significantly between the groups in sputum material.

In IS, as well as in BAL, smokers showed a higher percentage in macrophages $(\mathrm{p}<0.001 \mathrm{BAL}, \mathrm{p}<0.05$ IS $)$. The percentage of lymphocytes was decreased in BAL sam- ples from smokers, while no similar difference in lymphocyte proportions was detected comparing sputum samples from smokers and nonsmokers. The neutrophil and eosinophil proportions did not deviate significantly between smokers and nonsmokers in IS or BAL.

Smokers versus nonsmokers comparison of macrophage phenotypes in sputum and bronchoalveolar lavage, respectively

When comparing immunostaining results from the two groups, smokers macrophages showed a difference in phenotype compared to macrophages collected from nonsmokers. The same phenotypical variance between groups was detected in both BAL and sputum material; a significantly lower expression of RFD1 $(\mathrm{p}<0.01$ IS, $\mathrm{p}<0.05$ BAL), RFD7 ( $<<0.05$ IS, $p<0.05$ BAL), CD54 ( $<<0.05$ both) and CD71 ( $<<0.05$ both) in smokers macrophages compared with nonsmokers macrophages. The expression of CD11b, CD68 and HLA-DR did not differ significantly between the groups.

\section{Discussion}

In the present study it was demonstrated that the total cell count and the relative proportions between leukocytes differed in IS and BAL material collected from healthy individuals. Sputum contained fewer cells, a lower percentage of macrophages, a lower proportion of lymphocytes (in nonsmokers), but a larger percentage of neutrophils than BAL fluid. The eosinophil cell count did not differ

Table 3. - Intraindividual comparisons of the percentage of macrophages positive for intracellular and surface markers in bronchoalveolar lavage (BAL) fluid and induced sputum (IS) from smokers and nonsmokers

\begin{tabular}{|c|c|c|c|c|c|c|c|}
\hline & \multicolumn{2}{|c|}{ Smokers } & \multicolumn{2}{|c|}{ Nonsmokers } & \multicolumn{3}{|c|}{ Total population } \\
\hline & $\underset{n=9}{I S}$ & $\begin{array}{l}\text { BAL } \\
n=9\end{array}$ & $\begin{array}{c}\text { IS } \\
n=7\end{array}$ & $\begin{array}{l}\text { BAL } \\
n=7\end{array}$ & $\underset{n=16}{\text { IS }}$ & & $\begin{array}{l}\text { BAL } \\
n=16\end{array}$ \\
\hline RFDI & $62.0(42.0-62.5)$ & $70.0(52.0-71.0)^{+}$ & $82.0(0.71-86.0)$ & $71.0(69.0-86.0)^{+}$ & $69.9(60.0-80.0)$ & 70.0 & $(63.5-74.0)^{+}$ \\
\hline RFD7 & $55.0(50.0-61.0)$ & $48.0(39.0-54.0)^{*}$ & $75.0(62.0-86.0)$ & $58.0(50.0-64.0)^{+}$ & $62.0(53.5-74.5)$ & 53.0 & $(44.0-60.0)^{* *}$ \\
\hline CD11b & $49.5(22.0-53.0)$ & $52.0(40.0-56.0)^{+}$ & $54.0(52.0-64.0)$ & $46.0(40.0-58.0)^{+}$ & $54.0(47.0-54.5)$ & 51.0 & $(42.0-58.0)^{+}$ \\
\hline CD54 & $33.0(14.0-43.0)$ & $34.0(26.0-37.5)^{+}$ & $64.0(58.0-73.0)$ & $45.0(43.0-46.0)^{*}$ & $58.0(25.0-64.0)$ & 42.5 & $(30.5-45.0)^{*}$ \\
\hline CD68 & $43.0(37.0-55.0)$ & $35.0(26.0-54.0)^{+}$ & $61.0(54.0-81.0)$ & $34.0(28.0-44.0)^{+}$ & $54.0(42.0-62.0)$ & 34.5 & $(26.0-45.0) *$ \\
\hline CD71 & $70.5(65.0-83.0)$ & $60.0(55.5-67.0)^{*}$ & $85.0(77.0-89.0)$ & $70.0(68.0-76.0)^{*}$ & $78.0(68.0-85.0)$ & 68.0 & $(56.0-73.0)^{* *}$ \\
\hline HLA-DR & $92.0(86.0-95.0)$ & $88.0(69.0-95.0)^{+}$ & $98.0(96.0-99.0)$ & $96.0(85.0-99.0)^{+}$ & $96.0(90.0-98.5)$ & 95.0 & $(76.0-98.0)^{+}$ \\
\hline
\end{tabular}

The data are presented as medians of percentage values with upper and lower quartile values. HLA: human leukocyte antigen. *: $\mathrm{p}<0.05$, between IS and BL; **: $\mathrm{p}<0.01$, between IS and BAL; +: Ns. Comparisons were made using Wilcoxon's matched pairs test. 
between IS and BAL material. When analysing macrophage antigen expression in IS and BAL there was a higher percentage of sputum macrophages expressing RFD7 (in smokers and total population), CD71 (in smokers and nonsmokers), CD54 (in nonsmokers and total population) and CD68 (in total population) than BAL macrophages.

The relative differences in proportions of leukocytes found in healthy individuals compares fairly well to the results of FAHY et al. [12], who compared IS and BAL from healthy nonsmokers and to the results of investigators demonstrating similar relative differences between cell types in sputum and BAL from patients with asthma and/ or chronic bronchitis $[1,2,13]$.

The distribution of cell types has been shown to vary in different lung compartments; in the alveoli the macrophage is the predominant cell type, while the percentage of neutrophils increases in more proximal parts of the airways [11]. Comparing airway lining lavage fluid (ALF), material recovered with a method that allows selective studies of cells from the airways, with BAL fluid, RANkIN $e t$ al. [11] found a significantly higher percentage of neutrophils in ALF from healthy individuals.

After correcting for differences in cell-counting methods (the differential cell counts in the other studies included epithelial and unidentifiable cells, where as ours did not), the ALF macrophage and neutrophil cell count data demonstrated by RaNkIN et al. [11] corresponded well to the IS cell-count results. Taken together, these data suggest that IS may provide material similar to that obtained by ALF.

Pulmonary macrophages have among other functions been postulated to perform a regulatory role, establishing immunological balance in the lungs, by stimulating or suppressing T-cells [14-17]. These activities are performed by functionally different and phenotypically distinct populations of macrophages, which have been proposed to be identifiable using combinations of the monoclonal antibodies RFD1 and RFD7 [18]. RFD1 recognizes antigenpresenting cells, while the RFD7 epitope is expressed by mature phagocytes. In a study of T-cell and macrophage subsets in the human, normal bronchial wall, PowER et al. [19] demonstrated dominant proportions of macrophages expressing a suppressor phenotype (RFD1+RFD7+, 46\%), or an effector phenotype (RFD1-RFD7+, 44\%) over those with an inducer phenotype (RFD1+RFD7-, 11\%). With reservations for not using a double-staining technique when studying the expression of RFD1 and RFD7, sputum material was found to contain a higher percentage of macrophages expressing RFD7 compared with BAL material. Moreover, sputum macrophages generally showed a higher expression of CD71, an antigen that has been described as characteristic for proliferating macrophages [20].

When comparing BAL and IS from the total population, sputum macrophages showed a higher expression of CD68, a lysosomal granulae-associated epitope expressed by macrophages and negative for antigen-presenting cells [21]. Taken together, these results could lead to the presumption that macrophages collected using induced sputum represent maturing or phenotypically mature macrophages. Any functional differences corresponding to the phenotypic difference between the airway and alveolar macrophage populations remain to be elucidated. Nonsmokers sputum material contained a higher percentage of macrophages, positive for the adhesion molecule CD54, in contrast to their BAL fluid. A similar difference could not be found in smokers' macrophages. Hypothetically, this divergence could be attributed to the generally lower expression of CD54 in smokers' sputum or BAL material shown in this study as well as in other reports [22]. However, that hypothesis should, then, also be true for other markers expressed differently by smokers and nonsmokers macrophages.

The present results show that the macrophage expression of HLA-DR is similar in IS and BAL, a result in keeping with those of RANKIN et al. [11], who found no difference in HLA-DR expression between ALF and BAL macrophages. HLA class II seems to be constitutively expressed on nonsmokers' alveolar macrophages [23]. Functional studies should be undertaken to investigate any differences in antigen-presenting capacity between macrophage populations hypothetically derived from different departments of the lung.

In order to investigate any DTT-mediated effect on immunocytochemical staining results for the antibodies used in this study, a number of BAL samples was incubated with DTT before processing. When comparing the immunocytochemical staining results of these samples, with samples not exposed to DTT collected at the same time and from the same individual, there was no difference in the expression of any of the seven antibodies used. This indicates that induced sputum can be utilized in immunocytochemical studies of the cell-surface markers that were accounted for.

In the present study, sputum analyses were performed on the whole expectorated samples, without separating sputum plugs from saliva. According to the authors' experience, this is a reliable method by which to retrieve sputum material from healthy subjects. IN'T VeEN et al. [24], in a recent work, demonstrated good repeatability of cell differentials in whole sample sputum analysis. Our meth-od resulted in a varying percentage of squamous cell contamination, but the general cytospin quality was very high. No case had to be excluded owing to sputum squamous cell contamination over $80 \%$.

In conclusion, this study has demonstrated that material collected with induced sputum and bronchoalveolar lavage differs in total as well as differential cell counts. Macrophages recovered with induced sputum seem to be expressing a phenotype somewhat different from that of bronchoalveolar lavage macrophages. Furthermore, effects mediated by dithiothreitol on pulmonary macrophage immunocytochemical staining results for markers used in this study was excluded. Presuming that macrophages collected with induced sputum derive from the airways rather than the alveoli and considering the tendency of increased expression of cell-surface epitopes characteristic for maturing or mature, effector phagocytes on induced sputum macrophages, the results could imply that the airways are inhabited by mature macrophages, serving a function somewhat different from that of the alveolar macrophages. The results obtained from analysing induced sputum in healthy individuals could possibly offer a baseline against which sputum cell counts in different pathological conditions could be compared.

Acknowledgements: The authors wish to thank M. Dahl, B. Dahlberg and M. Hallgren for excellent technical assistance. 


\section{References}

1. Keatings VM, Evans DJ, O'Connor BJ, Barnes PJ. Cellular profiles in asthmatic airways: a comparison of induced sputum, bronchial washings, and bronchoalveolar lavage fluid. Thorax 1997; 52: 372-374.

2. Grootendorst DC, Sont JK, Willems LNA, et al. Comparison of inflammatory cell counts in asthma: induced sputum $v s$ bronchoalveolar lavage and bronchial biopsies. Clin Exp Allergy 1997; 27: 769-779.

3. Pizzichini MM, Pizzichini E, Clelland L, et al. Sputum in severe exacerbations of asthma: kinetics of inflammatory indices after prednisone treatment. Am J Respir Crit Care Med 1997; 155: 1501-1508.

4. Keatings VM, O'Connor BJ, Wright LG, Huston DP, Corrigan $\mathrm{CJ}$, Barnes PJ. Late response to allergen is associated with increased concentrations of tumor necrosis factor alpha and IL-5 in induced sputum. $J$ Allergy Clin Immunol 1997; 99: 693-698.

5. Iredale MJ, Wanklyn SAR, Phillips IP, Krausz T, Ind PW. Non-invasive assessment of bronchial inflammation in asthma: no correlation between eosinophilia of induced sputum and bronchial responsiveness to inhaled hypertonic saline. Clin Exp Allergy 1994; 24: 940-945.

6. Fahy JV, Liu J, Wong H, Boushey HA. Analysis of cellular and biochemical constituents of induced sputum after allergen challenge: a method for studying allergic airway inflammation. J Allergy Clin Inmunol 1994; 93: 1031-1039.

7. Claman DM, Boushey HA, Liu J, Wong H, Fahy JV. Analysis of induced sputum to examine the effects of prednisone on airway inflammation in asthmatic subjects. J Allergy Clin Immunol 1994; 94: 861-869.

8. Fahy JV, Liu J, Wong H, Boushey HA. Cellular and biochemical analysis of induced sputum from asthmatic and from healthy subjects. Am Rev Respir Dis 1993; 147: 1126-1131.

9. Pin I, Freitag AP, O'Byrne PM, et al. Changes in the cellular profile of induced sputum after allergen-induced asthmatic responses. Am Rev Respir Dis 1992; 145: 1265-1269.

10. Popov T, Gottschalk R, Kolendowicz R, Dolovich J, Powers P, Hargreave FE. The evaluation of a cell dispersion method of sputum examination. Clin Exp Allergy 1994; 24: 778-783.

11. Rankin JA, Marcy T, Rochester CL, et al. Human airway macrophages. Am Rev Respir Dis 1992; 145: 928-933.
12. Fahy JV, Wong H, Liu J, Boushey HA. Comparison of samples collected by sputum induction and bronchoscopy from asthmatic and healthy subjects. Am J Respir Crit Care Med 1995; 152: 53-58.

13. Maestrelli P, Saetta M, Di Stefano A, et al. Comparison of leucocyte counts in sputum, bronchial biopsies, and bronchoalveolar lavage. Am J Respir Crit Care Med 1995, 152: 1926-1931.

14. Holt PG, McMenamin C, Schon-Hegrad MA, et al. Immunoregulation of asthma: control of T-lymphocyte activation in the respiratory tract. Eur Respir J 1991; 4: Suppl. 13, 6-15.

15. Strickland DH, Thepen T, Kees UR, Kraal G, Holt PG. Regulation of T-cell function in lung tissue by pulmonary alveolar macrophages. Immunology 1993, 80: 266-272.

16. Strickland DH, Kees UR, Holt PG. Suppression of T-cell activation by pulmonary alveolar macrophages: dissociation of effects on TcR, L-2R expression, and proliferation. Eur Respir J 1994; 7: 2124-2130.

17. Thepen T, Kraal G, Holt PG. The role of alveolar macrophages in regulation of lung inflammation. Ann N Y Acad Sci 1994; 725: 200-206.

18. Spiteri MA, Poulter LW. Characterization of immune inducer and suppressor macrophages from the normal human lung. Clin Exp Immunol 1991; 83: 157-162.

19. Power CK, Burke CM, Sreenan S, Hurson B, Poulter LW. T-cell and macrophage subsets in the bronchial wall of clinically healthy subjects. Eur Respir J 1994; 7: 437-441.

20. Trowbridge IS. Overview of CD71. In: Schlossman SF, Boumsell L, Gilks W, et al., eds. Leucocyte Typing V. Oxford, Oxford University Press, 1995; pp. 1139-1141.

21. Falini B, Flenghi L, Pileri S, et al. PG-M1: a new monoclonal antibody directed against a fixative-resistant epitope on the macrophage-restricted form of the CD68 molecule. Am J Pathol 1993; 142: 1359-1372.

22. Sköld CM, Lundahl J, Hallden G, Hallgren M, Eklund A. Chronic smoke exposure alters the phenotype pattern and the metabolic response in human alveolar macrophages. Clin Exp Immunol 1996; 106: 108-113.

23. Pankow W, Neumann K, Rüschoff J, Schroder R, von Wichert P. Reduction of HLA-DR antigen density on alveolar macrophages of smokers. Lung 1991; 169: 255-262.

24. in 't Veen JCCM, de Gouw HWFM, Smits HH, et al. Repeatability of cellular and soluble markers of inflammation in induced sputum from patients with asthma. Eur Respir J 1996; 9: 2441-2447. 